\title{
MPPT Design using Perturb \& Observe Method Combined with Fire Fly Algorithm
}

\author{
Udhayavinodhini.A ${ }^{1}$, P.Anbarasu ${ }^{2}$, G.Suresh ${ }^{3}$ \\ PG Student, Electrical and Electronics Department, Sri Eshwar College of Engineering, Coimbatore, India ${ }^{1}$ \\ Assistant Professor, Electrical and Electronics Department, Sri Eshwar College of Engineering, Coimbatore, India ${ }^{2,3}$
}

\begin{abstract}
The energy demand is increased now days and the non- renewable energies are produce high environmental hazards and its reduced by the renewable energy resources. In solar energy is convert electrical energy which help of photo voltaic (PV) generation. The solar energy efficacy reduced because of climatic change, so need to track maximum power point of PV. The maximum power point tracking (MPPT) methods like perturb-and-observe (P\&O) method is used to track only the first local maximum point (LMP) the progress. MPPT methods based on Fire Fly Algorithm (FA) used to track the global maximum point (GMP). But the problem associated with the FA algorithm is produce long time for searching the LMP. This paper reports a hybrid method, which combines P\&O and FA methods. First, the P\&O method is used to find the local maximum point. Then, starting from that point on, the FA method is used to search the GMP. The advantage of the proposed the time that is required for convergence improved.
\end{abstract}

Keywords: Photovoltaic (PV), Maximum Power Point Tracking (MPPT), Fire Fly (FA), Perturb \& Observe (P\&O).

\section{INTRODUCTION}

Recently most of the papers, many algorithms are used to track the maximum power point MPP) have been proposed. In this the hill climbing, perturb \& observe method is mostly used. These methods are calculating the MPP using different ways under the same fundamental concept. In these algorithms the first local maximum point (LMP) is reached means stop maximum point searching. This is the main drawback of these algorithms [10].

During shaded conditions the shaded cell in the panel is reverse biased and act as a load, so produce hot spot problem [3]. To avoid this problem the by-pass diode is used to conduct the current that is produced by the shaded cell of the solar panel. But the by-pass diodes will change the uniform current- voltage (I-V), power-voltage $(\mathrm{P}-\mathrm{V})$ characteristics of the solar module.

To maximize the efficiency of solar module by tracking global maximum point (GMP) from solar panel. Basically two approaches are used to find GMP. The first method is using the hard ware i.e. use of multilevel inverter but they produce complexity and costly. The second method is to track the GMP with help of control algorithms and the paper also discusses the control algorithms.

In this paper gives the hybrid of $\mathrm{P} \& \mathrm{O}$ and FA methods. Starting the P\&O method employed to identify the near local maximum point. From that point the FA used to search the GMP. The advantage of this hybrid convergence speed is greatly increased.

\section{PERTURB \& OBSERVE METHOD}

In this method perturbation is introduced in the system. Use of the perturbation the power will be changed. The power produced in the direction of perturbation. If the maximum power point is reached means the perturbation starts to decrease and produce the power in the reverse direction.

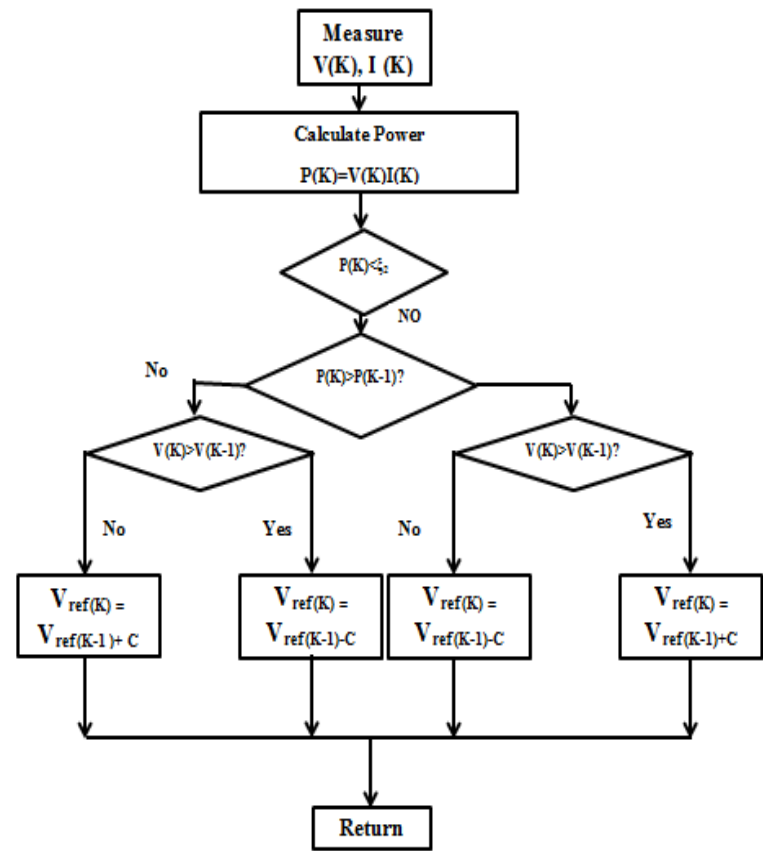

Fig.1Flow chart for P\&O method

The algorithm takes the value of voltage and current of solar panel. Power is calculated with help of voltage and current. The value of voltage and current are denoted by $\mathrm{k}^{\text {th }}$ instant [1] [6]. Next value of voltage and currents are mentioned $\mathrm{k}+1^{\text {th }}$ instant and the next instants are measured from the previous instants.

The previous and next instant power is compared. If the previous instant is greater means the right side curve will be executed otherwise its go to the left side. In that time the voltage are compared with that instants and depending upon the values the control voltage added or together.

The main drawback of the method is first local maximum point is reached means the searching will be stop in that 
place. So the global maximum point is not attained and no guarantee about the global maximum power point.

\section{III.FIRE FLY ALGORITHM}

The fire fly algorithm is type of soft computing techniques. Many of the algorithms used in MPPT previous like particle swarm optimization (PSO) [5] [11], ant colony algorithms (AC), genetic algorithm (GA).

This gives the detail about of FA algorithm. This algorithm is inspired by the flashing behaviour of fireflies to attract other fireflies for mating purpose.

The statistical analysis of the comparison clearly indicates that FA is potentially more powerful in finding global optima with least computing time [2] [14] [15] [16].

Firefly Algorithm, the following three assumptions are made:

1. All fireflies are unisex so that one firefly will be attracted to other fireflies regardless of their sex.

2. The attractiveness between two fireflies is proportional to relative brightness and the less bright one will move toward the brighter one. If there is no brighter one in a firefly colony, each one will move randomly.

3. The brightness of a firefly is affected or determined by the landscape of the objective function.

\section{A. Steps For Algorithm}

STEP 1: parameter setting, Fix the constants of the FA, population size $\mathrm{N}$, and the termination criterion.

In this algorithm, the position of the firefly is taken as a duty cycle of the dc-dc converter.

The brightness of each firefly is taken as generated power of the PV system, corresponding to the position of this firefly.

STEP 2: Initialization of Fireflies, In this step, the fireflies are positioned in the allowable solution space between dmin to dmax where dmin and dmax represent the minimum and maximum values of the duty ratio of the dc-dc converter.

STEP 3: Brightness Evaluation, in this step, the dc-dc converter is operated corresponding to the position of each firefly (i.e., duty ratio) sequentially.

STEP 4: Update the Position of Fireflies, The firefly with maximum brightness remains in its position and the remaining fireflies update their position based on

STEP 5: Terminate the program, if the termination criterion is reached, else go to step 3

STEP 6: Reinitiate the FA, if the solar insolation changes, which is detected by the digital controller by sensing the change in the power output.

\section{IV.PROPOSED METHOD}

\section{A. System Block Diagram}

The below diagram shows the overall scheme of solar system used in proposed method. It consists of solar panel, MPPT and load. Depending upon the irradiance values the solar panel produce the power. But it's not suitable for the applications.

So use of MPPT track the maximum power of solar panel which use of short circuit current and open circuit voltage.

Adjust the duty cycle with help of instantaneous power adjust a duty cycle depends upon the load requirement.

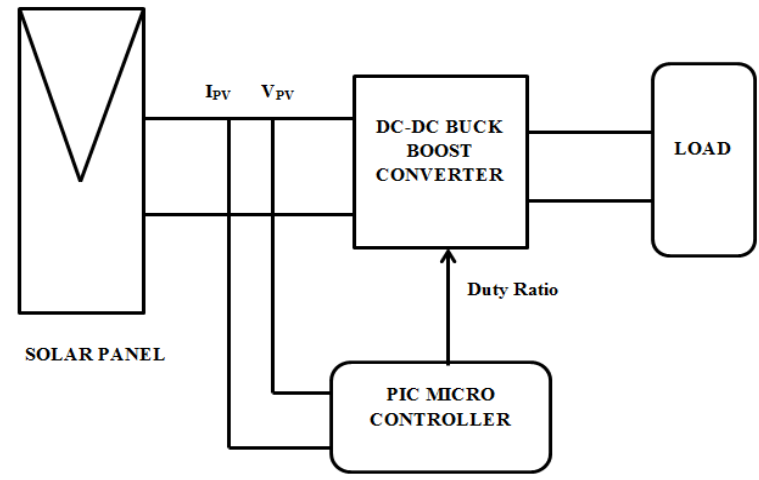

Fig. 2 block diagram of proposed method

\section{B. Hybrid Of P\&O With FA MPPT}

They described a new MPPT method that can be used to track the GMP when a PV panel is partially shaded due to environmental conditions and human activities. The proposed method is important for producing hybrid method of P\&O and FA [1]. The algorithm has been explained two stage.

In the first stage, the $\mathrm{P} \& \mathrm{O}$ method is employed to quickly search for the first LMP. The LMP is search by help of PV voltage, current.

The power is calculated from voltage and current. The power is compared with the tolerance value. Depending upon the tolerance value the LMP is start to searching.

Then, in the second stage, the FA is used to search the GMP. The GMP tracking is done by the steps followed by the fire fly algorithm. The search space in the second stage is reduced, allowing the GMP to quickly obtain.

The algorithms are used in MPPT like Perturb and Observe, fire fly algorithm, Perturb and Observe with Fire Fly algorithm also analysed.

Such this three methods the Perturb and Observe with Fire Fly Algorithm gives more attractiveness and reduced complexity, less oscillation in amplitudes of voltage, current, power. The flowchart of each algorithm explained and studied. 


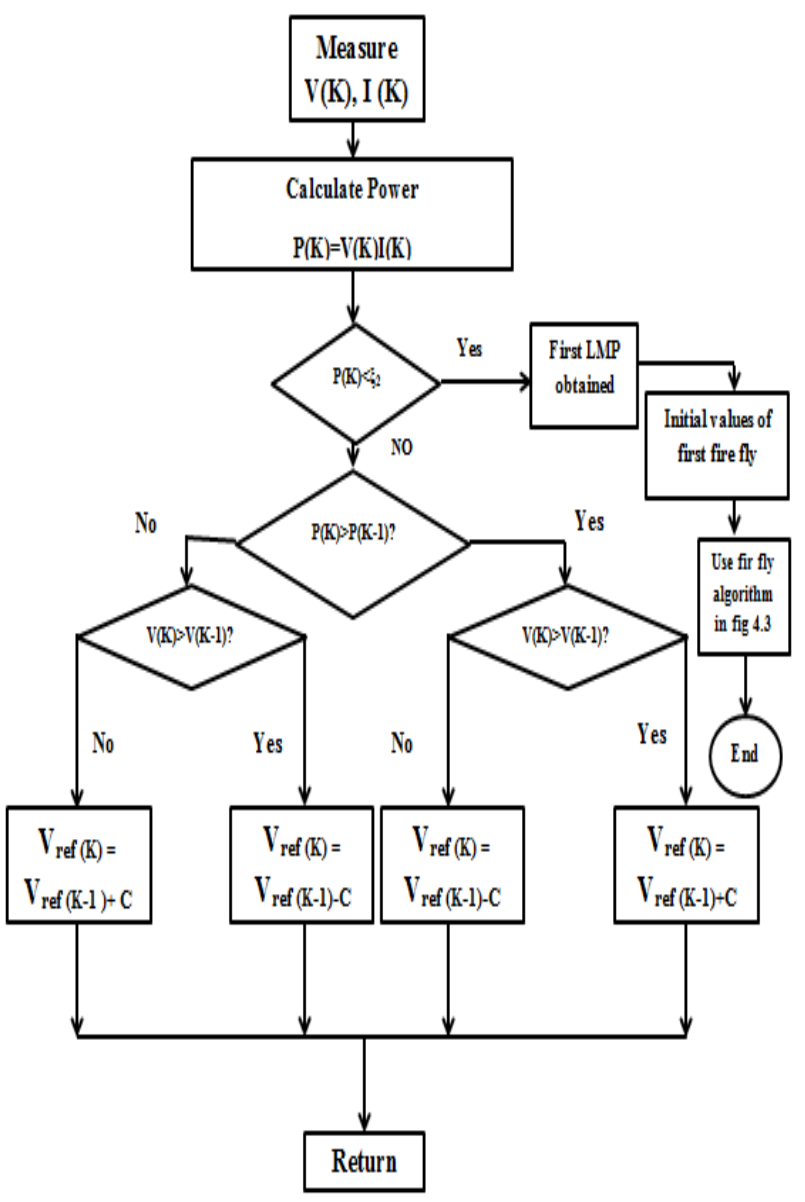

Fig.3 Flow chart for proposed method

\section{SIMULATION AND RESULT ANALYSIS}

The software used in this project for simulation is MATLAB R2013a. MATLAB is a high performance language for technical computation. It contains computation, visualization and programming in an easyto-use environment where problems and solutions are expressed in familiar mathematical notations.

Typical uses include math and computation algorithm, data acquisition, modelling, simulation, prototyping data analysis, scientific and engineering graphics application development.

Circuit shown in Figure 5.1 is simulated using SIMULINK tool in MATLAB. The simulation is carried by different conditions like fixed Irradiations and variable irradiance.

To investigate the performance of the proposed schemes using the $\mathrm{P} \& \mathrm{O}$ with FA method, a simulation model is developed for the overall system. It consists of PV model, MPPT controller, dc-dc boost converter.

The MPPT consists of two algorithms named as Perturb and Observe, Fire Fly Algorithm. In this MPPT the above two algorithms are combined to obtain maximum power. In simulation the output voltage, output current, output power of boost converter are represented in scope.

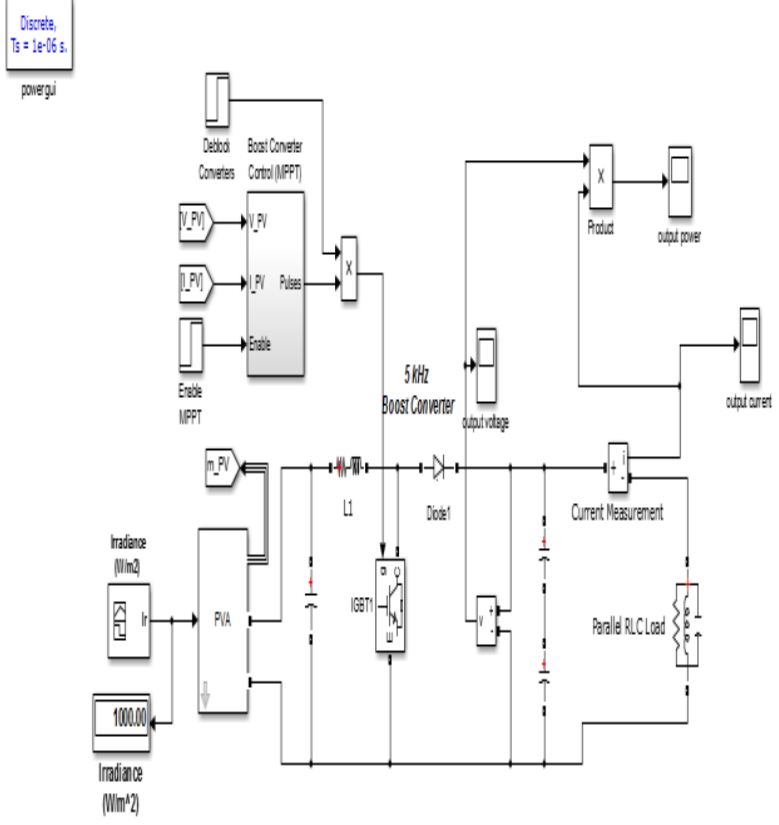

Fig.4 Simulation for hybrid MPPT

The graphs give detail about voltage (V), current(A) and power $(\mathrm{P})$ of the converter output for different irradiation values. The graphs are plotted between voltage (V) vs. time(S), current (A) vs. time(S) and power vs. time(S).

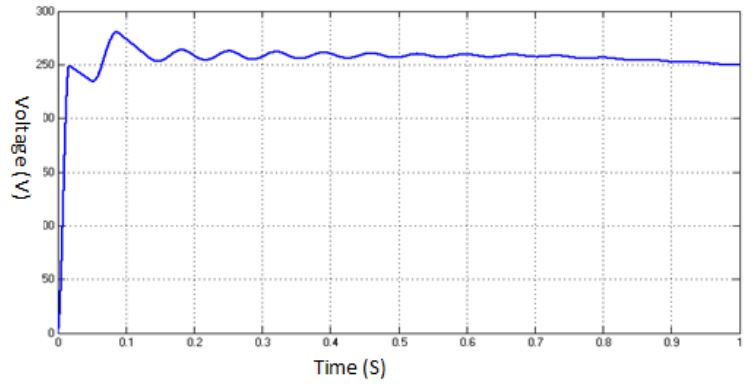

Fig. 5 Voltage (V) vs Time (S)

The above graphis the voltage characteristics with respect to time for constant values of irradiation. After 0.1 seconds time, the voltage reaches its steady state.

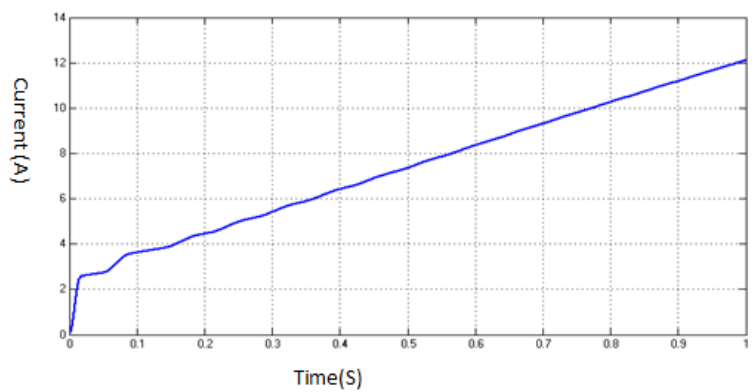

Fig. 6 Current (A) vs Time (S)

The above graphis the current characteristics with respect to time for constant values of irradiation. After 1 seconds time, the current reaches its steady state. 


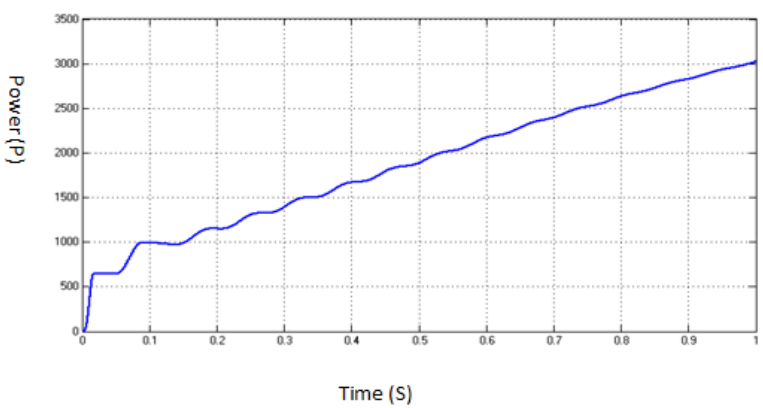

Fig.7Power(P) vs Time (S)

The above graph is the power characteristics with respect to time for variable values of irradiation. After 1 seconds time, the power reaches its steady state. Using the hybrid MPPT controller, the MPP (Maximum Power Point) is tracked and delivered to the load. There is no change in converter outputs because of MPPT.

\section{CONCLUSION}

This paper gives the new MPPT method used to track the GMP of the PV panel under varying environmental condition. The proposed method is important to combine $\mathrm{P} \& \mathrm{O}$ with FA to form a hybrid method. In first stage is used to find a LMP of PV panel use of P\&O algorithm. The second stage is used to find a GMP of the panel which help of FA algorithm. The FA reduces the complexity of finding GMP, reduce time convergence, improve dynamic performance and implemented in a low cost microcontroller.

\section{REFERENCES}

[1] Lian K. L., Jhang J. H., and Tian I. S.,(march 2014), "A Maximum Power Point Tracking Method Based on Perturb-and-Observe Combined With ParticleSwarm Optimization" IEEE journal of photovoltaics, vol. 4 , no. 2.

[2] KinattingalSundareswaran, SankarPeddapati, and SankaranPalani(june 2014), "MPPT of PV Systems Under Partial Shaded Conditions Through a Colony of Flashing Fireflies" IEEE transactions on energy conversion, vol. 29, no. 2.

[3] EL-Dein M. Z. S, Kazerani M., and Salama M. M. A.,( Jan. 2013) "Optimal photovoltaic array reconfiguration to reduce partial shading losses," IEEE Trans. Sustainable Energy, vol. 4.

[4] Lei P., Li J., and Seem J.,( Jul. 2011) "Sequential ESC-based global MPPT control for photovoltaic array with variable shading," IEEE Trans. Sustainable Energy, vol. 2.

[5] Miyatake M., Veerachary M., Toriumi F., Fujii N., and Ko H.,(Jan 2011) "Maximumpower point tracking of multiple photovoltaic arrays: A PSO approach,"'IEEE Trans. Aerospace Electron. Syst.,vol. 47, no.

[6] Fernia N., Petrone G., Spagnuolo G., and Vitelli M., (Jul 2005)"Optimization of perturb and observe maximum power point tracking method,"IEEETrans.Power Electronics. vol. 20.

[7] Esram T. and Chapman P. L.,( Jun 2007) "Comparison of photovoltaic array maximum power point tracking techniques," IEEE Trans. Energy Convers.,vol. 22.

[8] Suntio T., Leppaaho J., Huusari J., and Nousiainen L.,( Sep 2010) "Issues on solargenerator interfacing with current-fed MPP-tracking converters,"IEEE Trans. Power Electron., vol. 25.

[9] Bidram A., Davoudi A., and Balog R., (Oct 2012)"Control and circuit techniques to mitigate partial shading effects in photovoltaic arrays,"IEEE J. Photovoltaics, vol. 2.

[10] Roy Chowdhury S. and Saha H.,(june 2010) "Maximum power point tracking of partially shaded solar photovoltaic arrays,"Solar Energy Mater. Solar Cells, vol. 94.

[11] Ishaque K., Salam Z., Amjad M., and Mekhilef S.,( Aug 2012) “An improved particle swarm optimization (PSO)-based MPPT for PV with reduced steady-state oscillation,"IEEE Trans. Power Electron., vol. 27, no. 8 .

[12] Liu Y.-H., Huang S.-C., Huang J.-W., and. Liang W.-C, (Dec 2012)“A particle swarm optimization-based maximum power point tracking algorithm for PV systems operating under partially shaded conditions," IEEE Trans. Energy Convers., vol. 27, no. 4.

[13] K.Ishaque and Z. Salam, ( Aug. 2013) "A deterministic particle swarm optimization maximum power point tracker for photovoltaic system under partial shading condition,"IEEE Trans. Ind. Electron., vol. 60, no. 8

[14] Yang X.-S.,Nature-Inspired Metaheuristic Algorithm, Beckington, U.K.:Luniver Press, 2008

[15] Yang X.-S. "Firefly algorithms for multimodal optimization," in Proc.Stochastic Algorithms Foundations Appl. (SAGA),2009, vol. 5792,.

[16] Chandrasekaran K. and Simon S. P., (Feb.2013)"Optimal deviation based firefly algorithm tuned fuzzy design for multi-objective UCP,"IEEE Trans. PowerSyst., vol. 28, no. 1 .

[17] MihneaRosu-Hamzescu, SergiuOprea,Microchip Technology Inc. "Practical Guide to Implementing Solar Panel MPPT Algorithms"

[18] HamidrezaGhoddami, Student Member, IEEE, and AmirnaserYazdani, Senior Member, IEEE (April 2011) "A SingleStage Three-Phase Photovoltaic System With Enhanced Maximum Power Point Tracking Capability and Increased Power Rating" IEEE Transactions On Power Delivery, Vol. 26, No. 2

[19] Gamal M. Dousoky, Masahito Shoyama, and Haitham Abu-Rub, (2013) "Dual-Mode Controller for MPPT in Single-Stage GridConnected Photovoltaic Inverter" IEEE 